๖

OPEN ACCESS

EDITADO POR

- Eulália Leurquin

(UFC)

- Rita de Cássia Souto Maior

(UFAL)

- Matilde Alves Gonçalves

(UNL)

AVALIADO POR

- Silvio N. da Silva Júnior (UFAL)

- Adna de Almeida Lopes (UFAL)

SOBRE OS AUTORES

- Clara Regina

Conceptualização, Curadoria

de Dados, Investigação,

Validação, Visualização, Escrita

- rascunho original, Escrita -

análise e edição.

- Guilherme Moés

Conceptualização, Curadoria

de Dados, Investigação,

Validação, Visualização, Escrita

- rascunho original, Escrita -

análise e edição.

- Marcela de M. Cordeiro Eulálio

Conceptualização, Curadoria

de Dados, Investigação,

Validação, Visualização, Escrita - rascunho original, Escrita -

análise e edição.

DATAS

- Recebido: 30/00/2021

- Aceito: 05/11/2021

- Publicado: 23/12/2021

\section{COMO CITAR}

Regina, C.; Moés, G.; Eulálio, M.

M. C. (2021). A gestão e as

práticas em resumos

acadêmicos no subdomínio da

Enfermagem: rumo ao conceito

\title{
A gestão e as práticas em resumos acadêmicos no subdomínio da Enfermagem: rumo ao conceito de Política Linguística Disciplinar ${ }^{1}$
}

\author{
Clara REGINA (D) \\ Universidade Federal da Paraíba (UFPB) \\ Guilherme MOÉS (D \\ Universidade Federal da Paraíba (UFPB) \\ Marcela de Melo Cordeiro EULÁLIO (D) \\ Universidade Federal da Paraíba (UFPB)
}

\section{RESUMO}

No âmbito da Linguística Aplicada, a área de Política e Planejamento Linguístico, especialmente a Teoria da Gestão da Língua, permite a compreensão de que as escolhas linguísticas dos sujeitos se relacionam ao domínio em que estão inseridos. Nesse sentido, o contexto acadêmico é um domínio maior e as suas várias áreas disciplinares são subdomínios, que materializam diferentes políticas linguísticas top-down, por exemplo, em revistas científicas. Das orientações que estas apresentam, no processo de publicação científica, questiona-se: como se caracterizam as políticas linguísticas declaradas e praticadas em um periódico científico da área da Enfermagem? Objetiva-se, de modo geral, analisar as políticas linguísticas na gestão e nas práticas de resumos publicados em um periódico da área

\footnotetext{
${ }^{1}$ Este artigo se situa na categoria de contribuição do tipo Relatório de Pesquisa, porque é um "relatório final de um trabalho originado de uma pesquisa baseada em dados empíricos, usando metodologia científica” (REVISTA DA ABRALIN, 2021).
} 


\section{REVISTA DA ABRALIN}

de Política Linguística

Disciplinar. Revista da Abralin, v. 20, n. 3, p. 1324-1344, 2021. da Enfermagem. Especificamente, buscam-se: 1) caracterizar as normas de trabalhos científicos como políticas linguísticas top-down do subdomínio da Enfermagem, a partir do periódico selecionado, considerando a cultura disciplinar em que se insere; 2) descrever as práticas de escrita de resumos desse periódico; 3) comparar a gestão de resumos nesse periódico, em relação às práticas de escrita analisadas. Fundamenta-se, principalmente, nos estudos de Spolsky $(2004 ; 2009 ; 2012)$ e de Hyland $(2008 ; 2012$; 2014). Na metodologia de paradigma interpretativista (LIN, 2015), analisam-se 10 resumos da Revista Latino Americana de Enfermagem. O principal resultado desta pesquisa é a proposta do conceito de Política Linguística Disciplinar. As discussões tecidas evidenciam a constituição de letramentos acadêmicos, nessas práticas de escrita, bem como apontam para a possibilidade de atividades diversas de letramentos serem desenvolvidas em cursos de Graduação, particularmente em Enfermagem. ${ }^{2}$

\section{ABSTRACT}

In Applied Linguistics, the Linguistic Policies and Planning area, especially the Language Management Theory, allows for the understanding that the subjects' linguistic choices are related to the domain in which they are inserted. In this sense, the academic context is a larger domain and its various disciplinary areas are subdomains, which materialize different topdown linguistic policies, for example, in scientific journals. From the guidelines that these present in the process of scientific publication, the question is: how are the linguistic policies declared and practiced in a scientific journal in the field of Nursing characterized? The objective is, in general, to analyze the linguistic policies in the management and practices of abstracts published in a journal in the field of Nursing. Specifically, it seeks to: 1) characterize the norms of scientific works as top-down linguistic policies of the Nursing subdomain, based on the selected journal, considering the disciplinary culture in which it operates; 2) describe the abstract writing practices of this journal; 3) compare the management of abstracts in this journal, in relation to the writing practices analyzed. It is based mainly on studies by Spolsky $(2004 ; 2009 ; 2012)$ and Hyland (2008; 2012; 2014). Based on the interpretivist paradigm methodology (LIN, 2015), 10 abstracts from the Latin American Journal of Nursing are analyzed. The main result of this research is the proposal of the concept of Disciplinary

\footnotetext{
${ }^{2}$ Um agradecimento especial à Professora Dra. Socorro Cláudia Tavares de Sousa, pela orientação, com tanta maestria, desta pesquisa, decorrente de sua disciplina de Linguística Aplicada, no Programa de Pós-Graduação em Linguística (Proling/ UFPB). Agradecimento especial também à Capes, pelo incentivo de pesquisa.
} 


\section{REVISTA DA ABRALIN}

Language Policies. The discussions woven evidence the constitution of academic literacy in these writing practices, as well as pointing to the possibility of different literacy activities being developed in Undergraduate courses, particularly in Nursing.

\section{PALAVRAS-CHAVE}

Políticas Linguísticas Disciplinares. Resumos. Enfermagem.

\section{KEYWORDS}

Disciplinary Language Policies. Summaries. Nursing.

\section{Introdução}

A área de Política e Planejamento Linguístico (PPL), inserida no âmbito da Linguística Aplicada (SOUSA; SOARES; DIONÍSIO, 2020), apresenta-se como terreno fértil para discussões em torno dos gerenciamentos da(s) língua(s) em diferentes domínios (SPOLSKY, 2009). Nessa perspectiva, circunscrevem-se não só as normas explícitas, tais como acordos ortográficos ou cooficialização de línguas a serem usadas em determinados locais, mas, também, normas implícitas, muitas vezes, não percebidas e oriundas de convenções sociais.

Nessa área, Spolsky (2009) propõe uma Teoria da Gestão da Língua (TGL), que objetiva dar conta das escolhas linguísticas realizadas pelos falantes individuais, levando em consideração as regras da comunidade de fala em que estão inseridos. Através dessa teoria, o interesse investigativo deste trabalho repousa nas políticas linguísticas no ambiente acadêmico, especificamente no fato de os atores sociais utilizarem uma linguagem que materializa as crenças das diferentes culturas disciplinares. Nesse sentido, o contexto acadêmico é um domínio maior e os vários espaços disciplinares que o compõem são subdomínios, que materializam diferentes políticas linguísticas bottow-up, por exemplo, em revistas científicas. Assim, cada área disciplinar, considerada um subdomínio dentro do domínio acadêmico, pode ser compreendida em termos de políticas linguísticas, mediante escolhas linguísticas que as diferenciam umas das outras. Em razão disso, surge a necessidade de se construir a noção de Políticas Linguísticas Disciplinares (PLD) ${ }^{3}$, aqui entendida como escolhas linguísticas que se encontram imbricadas às crenças, normas e práticas de áreas disciplinares específicas.

No presente artigo, tais especificidades e variações são evidenciadas a partir da área da Enfermagem, selecionada para esta investigação. A escolha dessa área decorre do fato de que a cultura disciplinar a ela imbricada, dadas suas particularidades no tocante ao fazer ciência, revela políticas linguísticas singulares. Por essa razão, questionamo-nos: como se caracterizam as políticas

\footnotetext{
${ }^{3}$ Essa noção é desenvolvida, na seção de fundamentação teórica, e utilizada na seção de análise de dados.
} 


\section{REVISTA DA ABRALIN}

linguísticas declaradas e praticadas em um periódico da área de Enfermagem? A fim de responder tal questionamento, objetiva-se, de modo geral, neste trabalho, analisar as políticas linguísticas na gestão e nas práticas de resumos publicados em um periódico da área da Enfermagem. Especificamente, buscam-se: 1) caracterizar as normas de trabalhos científicos como políticas linguísticas topdown do subdomínio da Enfermagem, a partir do periódico selecionado, considerando a cultura disciplinar em que se insere; 2) descrever as práticas de escrita de resumos desse periódico; 3) comparar a gestão de resumos nesse periódico em relação às práticas de escrita analisadas.

Diante dos objetivos, o desenvolvimento deste trabalho se alicerça em duas hipóteses. A primeira é a de que as normas apresentadas pela revista científica exerçam o poder de políticas linguísticas top-down sobre os resumos produzidos pelos autores, funcionando como uma força centrípeta. A segunda é a de que os resumos publicados nessa revista atendam às políticas linguísticas por ela normatizada; isso porque, caso contrário, estariam sujeitos a forças de coerção que inviabilizariam suas publicações no periódico.

A importância deste trabalho se justifica porque o conhecimento acerca das políticas linguísticas que materializam as crenças das diferentes culturas disciplinares é fundamental para apropriação, pelos acadêmicos, nas suas práticas de letramento acadêmico, da escrita dos gêneros acadêmicos, especialmente em se tratando do resumo, gênero focalizado neste trabalho. Além do que essa compreensão possibilita aos docentes planejar melhor suas aulas, sob uma perspectiva disciplinar, no sentido de favorecer aos alunos de determinada área do saber, neste caso, Enfermagem, maior conhecimento e consciência das políticas linguísticas explícitas em processo, em revistas acadêmicocientíficas. Com isso, a aprendizagem da escrita acadêmica se atrela ao desenvolvimento de letramentos acadêmicos (STREET, 2010) constituídos em atividades crítico-sociais orientadas. Ainda, o conhecimento dos atores sociais - os pesquisadores que submetem e publicam nesse periódico quanto a essas PLD é peça-chave para a divulgação do fazer científico, uma vez que a compreensão dessas políticas faz com que essas produções sejam aceitas e publicadas mais facilmente.

Dado o exposto, realizou-se uma pesquisa de natureza aplicada, quanto aos objetivos, e bibliográfica e documental, quanto aos procedimentos de coleta de análise de dados (CRESWELL, 2014; CROCKER, 2009; SILVEIRA; CÓRDOVA, 2009). Os dados coletados - que incluem as normas da Revista Latino Americana de Enfermagem, periódico Qualis A1 (CAPES, 2016), e dez (10) resumos dessa revista - são analisados à luz das noções teóricas de Spolsky (2004; 2009; 2012). Ademais, são considerados, para análise, os pressupostos de Hyland (2008; 2012; 2014), tomando-se os mais diversos discursos presentes no ambiente acadêmico, a partir dos quais o autor analisa as culturas disciplinares.

Finalmente, em termos de organização, além das considerações iniciais e finais, este artigo apresenta três tópicos principais. O primeiro desses é a metodologia, em que são apresentados os procedimentos metodológicos empreendidos para a execução da pesquisa que gerou este trabalho. $\mathrm{O}$ segundo, a fundamentação teórica, Perspectivas da Política e Planejamento Linguístico (PPL): da Teoria da Gestão da Língua (TGL) à Política Linguística Disciplinar (PLD), apresenta, ainda, o subtópico em que é desenvolvido o conceito de PLD. O terceiro compreende a análise de dados, intitulada As práticas de publicação de resumos da Enfermagem: uma análise de Políticas Linguísticas Disciplinares, 


\section{REVISTA DA ABRALIN}

em que são desenvolvidas as duas categorias de análise, a saber: As normas das revistas da Enfermagem e Normativas e práticas da área da Enfermagem.

\section{Metodologia: percurso para a análise de práticas linguísticas em periódico A1 que publica em Língua Portuguesa}

O percurso metodológico empreendido neste trabalho se situa em um paradigma de pesquisa interpretativista (LIN, 2015), dado o interesse prático subjacente de compreender determinadas ações sociais. Como apontado por Lin (2015), esse paradigma segue o propósito de construir conhecimentos em torno da compreensão do que atores sociais fazem, como fazem e por qual motivo o fazem. Assim, neste estudo, tal compreensão é analisada mediante normas e práticas linguísticas de resumos publicados, em Língua Portuguesa, em um periódico científico de Enfermagem Qualis A1. Nesse caminho da descoberta de significados, realizou-se uma investigação de natureza aplicada, quanto aos objetivos, e bibliográfica e documental, quanto aos procedimentos de coleta de análise de dados (CRESWELL, 2014; CROCKER, 2009; SILVEIRA; CÓRDOVA, 2009).

A escolha da Revista Latino Americana de Enfermagem, como representativa do subdomínio da Enfermagem, inserido no domínio acadêmico, parte das discussões de Barata (2016), Rodacki (2016) e de Soma, Alves e Yanasse (2016) acerca tanto do sistema de avaliação do Qualis Periódicos da Coordenação de Aperfeiçoamento de Pessoal do Ensino Superior (Capes), bem como das áreas de produção do conhecimento científico, reconhecidas por esta agência de institucionalização e aperfeiçoamento da formação acadêmica do nosso país.

Embora se concorde com os questionamentos desses autores sobre as problemáticas da estratificação dos periódicos, a escolha desse estrato (A1) acontece pelo aspecto de ele liderar o nível mais elevado da qualidade da avaliação pela Capes (2016), qual seja, a última divulgação do WebQualis. É importante salientar que, antes de selecionar a revista da Enfermagem, foi realizado, na Plataforma Sucupira, um levantamento de todos os periódicos A1, de acordo com as grandes áreas de conhecimento da Capes, a fim de se saber quais periódicos desse estrato publicam em língua portuguesa; uma vez que se partiu da hipótese de que, especialmente nas áreas das Ciências Exatas e da Saúde, as publicações em língua inglesa predominam, como se pode observar no Quadro 1. 


\section{REVISTA DA ABRALIN}

\begin{tabular}{|c|c|c|c|}
\hline Grande Área & Área de Avaliação & $\begin{array}{c}\text { Quantidade de registros de } \\
\text { periódicos A1 que publicam } \\
\text { em LP }\end{array}$ & $\begin{array}{l}\text { Quantidade de registros de } \\
\text { periódicos A1 que não } \\
\text { publicam em LP - publicações } \\
\text { em LE } / \mathrm{LI}^{4}\end{array}$ \\
\hline \multirow{4}{*}{ Agrárias } & Ciência de Alimentos & 0 & 83 \\
\hline & Ciências Agrárias I & 0 & 462 \\
\hline & Medicina Veterinária & 0 & 274 \\
\hline & $\begin{array}{l}\text { Zootecnia e Recursos } \\
\text { Pesqueiros }\end{array}$ & 0 & 151 \\
\hline \multirow{4}{*}{ Biológicas } & Biodiversidade & 0 & 243 \\
\hline & Ciências Biológicas I & 0 & 340 \\
\hline & Ciências Biológicas II & 0 & 377 \\
\hline & Ciências Biológicas III & 0 & 213 \\
\hline \multirow{9}{*}{ Saúde } & Educação Física & 2 & 237 \\
\hline & Enfermagem & 2 & 180 \\
\hline & Farmácia & 0 & 306 \\
\hline & Medicina I & 0 & 504 \\
\hline & Medicina II & 0 & 481 \\
\hline & Medicina III & 0 & 209 \\
\hline & Nutrição & 0 & 149 \\
\hline & Odontologia & 0 & 277 \\
\hline & Saúde Coletiva & 0 & 345 \\
\hline \multirow{5}{*}{$\begin{array}{l}\text { Ciências } \\
\text { Exatas e da } \\
\text { Terra }\end{array}$} & Astronomia e Física & 0 & 98 \\
\hline & Ciência da Computação & 0 & 152 \\
\hline & Geociências & 0 & 145 \\
\hline & Matemática, Prob. e Est. & 0 & 120 \\
\hline & Química & 0 & 245 \\
\hline \multirow{5}{*}{$\begin{array}{l}\text { Multidisciplin } \\
\text { ar }\end{array}$} & Biotecnologia & 0 & 428 \\
\hline & Ciências Ambientais & 0 & 462 \\
\hline & Ensino & 60 & 85 \\
\hline & Interdisciplinar & 37 & 931 \\
\hline & Materiais & 0 & 193 \\
\hline \multirow{4}{*}{ Engenharias } & Engenharias I & 0 & 231 \\
\hline & Engenharias II & 0 & 326 \\
\hline & Engenharias III & 0 & 382 \\
\hline & Engenharias IV & 0 & 214 \\
\hline \multirow{2}{*}{$\begin{array}{l}\text { Linguística } \\
\text { e Literatura }\end{array}$} & Artes e Música & 10 & 16 \\
\hline & Linguística e Literatura & 43 & 64 \\
\hline \multirow{6}{*}{$\begin{array}{c}\text { Sociais } \\
\text { Aplicadas }\end{array}$} & $\begin{array}{c}\text { Adm., Ciên. Cont. e } \\
\text { Turismo }\end{array}$ & 0 & 323 \\
\hline & Arquitetura e Urbanismo & 0 & 84 \\
\hline & $\begin{array}{l}\text { Comunicação e } \\
\text { Informação }\end{array}$ & 9 & 46 \\
\hline & Direito & 77 & 50 \\
\hline & Economia & 0 & 114 \\
\hline & $\begin{array}{c}\text { Plan. Urb. e } \\
\text { Reg./Demografia }\end{array}$ & 9 & 77 \\
\hline
\end{tabular}

${ }^{4}$ Leia-se: Língua Estrangeira (LE) e Língua Inglesa (LI). 


\section{REVISTA DA ABRALIN}

\begin{tabular}{|c|c|c|c|}
\hline & Serviço Social & 6 & 6 \\
\hline Antropologia \& & Arqueologia & 3 & 54 \\
\hline & $\begin{array}{c}\text { Ciên. Polít. e Relações } \\
\text { Inter. }\end{array}$ & 21 & \\
\hline & $\begin{array}{c}\text { Ciências da Religião e } \\
\text { Teologia }\end{array}$ & & 12 \\
\hline \multirow{4}{*}{ Humanas } & Educação & 16 & 62 \\
\hline & Filosofia & 59 & 28 \\
\hline & Geografia & 11 & 121 \\
\hline & História & 6 & 45 \\
\hline & Psicologia & 34 & 188 \\
\hline & Sociologia & 12 & 51 \\
\hline
\end{tabular}

QUADRO 1 - Levantamento de periódicos A1 que publicam em Língua Portuguesa (LP). Fonte: Elaboração própria, com base na Plataforma Sucupira ${ }^{5}$, em setembro de 2020.

A partir desse levantamento, é possível ilustrar a predominância de revistas com Qualis A1 com títulos em língua inglesa, principalmente, nas áreas de ciências biológicas e ambientais. De modo geral, em todas essas áreas, há um acervo de mais de mil revistas, visto como um meio em potencial para coleta de dados. É necessário ressaltar que algumas destas revistas, como pudemos perceber ao analisar o propósito de publicação delas, publicam em inglês e em português. Em outras palavras, para se ter certeza de que tais periódicos não aceitam textos em língua portuguesa, é preciso analisar criteriosamente as normas de submissão de cada revista. Diante dessa vastidão de possibilidades, o Quadro 1 evidencia o percurso de escolha dos periódicos A1 que publicam em Língua Portuguesa.

Após a escolha do periódico de Enfermagem, dentre os dois que publicam em Língua Portuguesa $^{6}$, como se pode ver no quadro acima, selecionamos 10 resumos, por ordem de publicação, do primeiro número/volume de 2020, mais recente, da Revista Latino-Americana de Enfermagem ${ }^{7}$, representante da área de Saúde, conforme ilustrado no Quadro 2.

\footnotetext{
${ }^{5}$ Disponível em: https://sucupira.capes.gov.br/sucupira/public/consultas/coleta/veiculoPublicacaoQualis/listaConsultaGeralPeriodicos.jsf. Acesso em set. 2020.

${ }^{6}$ Seleciona-se a Revista Latino Americana de Enfermagem porque, além de ser Qualis A1, é um periódico da Universidade de São Paulo, uma das instituições públicas mais reconhecidas do país.

${ }^{7}$ Disponível em: < http://www.rlae.eerp.usp.br/section/1/sobre-a-revista>. Acesso em out. 2020.
} 


\section{REVISTA DA ABRALIN}

\begin{tabular}{|c|c|c|c|}
\hline Área & Título do trabalho & $\begin{array}{l}\text { Quantidade de } \\
\text { autores }\end{array}$ & Sigla \\
\hline \multirow{10}{*}{ Enfermagem } & $\begin{array}{l}\text { Validação de um guia de aconselhamento para a } \\
\text { adesão ao tratamento antirretroviral usando } \\
\text { ciência da implementação }\end{array}$ & 5 autores & E1 \\
\hline & $\begin{array}{c}\text { Desenvolvimento de um guia de orientação } \\
\text { para instrutores: "Três Estágios do Debriefing } \\
\text { holístico" }\end{array}$ & 2 autores & E2 \\
\hline & $\begin{array}{l}\text { Influência do consumo de tabaco e álcool, de } \\
\text { hábitos alimentares e atividade física em } \\
\text { estudantes de enfermagem }\end{array}$ & 3 autores & E3 \\
\hline & $\begin{array}{l}\text { Análise da evolução de competências da prática } \\
\text { clínica no curso de enfermagem }\end{array}$ & 6 autores & $\mathrm{E} 4$ \\
\hline & $\begin{array}{l}\text { Fatores associados aos riscos de adoecimento } \\
\text { da equipe de enfermagem no trabalho em } \\
\text { instituição psiquiátrica }\end{array}$ & 6 autores & E5 \\
\hline & $\begin{array}{l}\text { Percepção e manifestação de competências } \\
\text { colaborativas em discentes da graduação em } \\
\text { saúde }\end{array}$ & 6 autores & E6 \\
\hline & $\begin{array}{l}\text { Propriedades psicométricas do questionário de } \\
\text { percepção da ameaça da doença crônica em } \\
\text { pediatria }\end{array}$ & 6 autores & E7 \\
\hline & $\begin{array}{l}\text { Acidentes de trabalho em crianças e jovens em } \\
\text { ambiente rural no Sul do Brasil }\end{array}$ & 4 autores & E8 \\
\hline & $\begin{array}{c}\text { Elaboração de um roteiro de avaliação de } \\
\text { administração segura de medicamentos em } \\
\text { estudantes de enfermagem }\end{array}$ & 4 autores & E9 \\
\hline & $\begin{array}{c}\text { Conhecimento e interesse em usar o dispositivo } \\
\text { intrauterino entre mulheres usuárias de } \\
\text { unidades de saúde }\end{array}$ & 6 autores & E10 \\
\hline
\end{tabular}

QUADRO 2 - Sobre os resumos coletados para análise.

Fonte: Elaboração própria, com base nos periódicos em recorte.

Deve-se esclarecer que a quantidade de resumos coletados se deu por causa da limitação metodológico-temporal de analisar a totalidade de 118 resumos, presentes no primeiro volume publicado no ano de 2020, pela respectiva revista. Sendo assim, coletamos os 10 resumos por ordem de publicação no número, antes de lê-los e avaliá-los.

No que tange aos procedimentos de análise dos resumos selecionados, a fim de se averiguar as PLD, considerando-se a gestão realizada pela revista, analisam-se comparativamente, a partir das normas explícitas para submissão de trabalhos científicos, as políticas linguísticas declaradas nas revistas para a produção de resumos na área em questão. Assim, a análise é dividida em duas categorias, sendo a primeira intitulada As normas da revista. Com essa categoria, analisa-se o conteúdo temático dos textos-discursos das normas para elaboração dos resumos presentes no periódico, destacando a natureza das orientações. Na segunda categoria, intitulada Normativas e práticas da 


\section{REVISTA DA ABRALIN}

área da Enfermagem, visando a analisar as práticas linguísticas, comparam-se os resumos às normas do periódico.

É importante ressaltar que, para além do tratamento analítico-interpretativista do corpus, considerando os aspectos que caracterizam as políticas linguísticas top-down, nas normas para produção dos resumos acadêmicos na revista, houve, também, um levantamento quantitativo. Neste, identificam-se os resumos publicados no periódico que foram implementados/planejados em conformidade com as diretrizes normativas das revistas, em termos de elementos composicionais apresentados na construção do resumo de artigo científico.

\section{Perspectivas da Política e Planejamento Linguístico (PPL): da Teoria da Gestão da Língua (TGL) à Política Linguística Disciplinar (PLD)}

Para melhor compreender a Teoria da Gestão da Língua (TGL) e a PLD que intitulam este tópico, fazse premente realizar um percurso histórico em torno da Política e Planejamento Linguístico (PPL), área disciplinar originada após a Segunda Guerra Mundial. De acordo com Ricento (2000), existem, na literatura da PPL, três etapas proeminentes na construção do campo em questão, sendo elas vislumbradas por três critérios: a macro sociopolítica, relacionada aos eventos nacionais e supranacionais, tais como a globalização, a expansão da área de comunicação, dentre outros; a epistemológica, ligada a paradigmas do conhecimento científico, como estruturalismo e pós-modernismo; assim como a estratégica, observada nas razões pelas quais os pesquisadores realizam suas investigações (RICENTO, 2000; SOUSA, PONTE; SOUSA-BERNINI, 2019).

Para compreender melhor as etapas de desenvolvimento da PPL, oriundas desses fatores, percebe-se que, na primeira, ocorrida entre a década de 60 e 70, os estudiosos da área concebiam o planejamento linguístico como uma atividade técnica, a qual favorecia, de alguma maneira, a constituição geopolítica do Estado-Nação: seja pela relação existente entre a unificação de uma região ou nação e o planejamento linguístico; seja pela utilização da língua como um recurso; seja pelos planejamentos de status e de corpus, concebidos como elementos não relacionados; seja, até mesmo, por uma concepção de língua que desconsiderava o contexto histórico, social e político, considerando, por sua vez, a diversidade linguística como um problema. Isso permite a compreensão de que, nesse primeiro momento da PPL, a área parecia servir como um recurso apenas para forjar a relação entre uma língua e uma nação, o que favorece pensar, por exemplo, a relação política e econômica das línguas coloniais utilizadas.

Na segunda etapa, que ocorreu entre as décadas de 70 e 80, estudiosos do planejamento linguístico começaram a refletir sobre a viabilidade dos modelos anteriores de planejamento linguístico (JOHNSON; RICENTO, 2013). Com isso, questionou-se o fato de as línguas serem socialmente controladas pelos grupos dominantes, de modo que as línguas indígenas estariam atreladas a funções 


\section{REVISTA DA ABRALIN}

sociais mais baixas, enquanto as línguas europeias eram usadas para as funções superiores, o que denotava o poder do colonialismo. Logo, nesse momento, os pesquisadores começaram a pensar na importância dos aspectos socioculturais na elaboração dos planejamentos linguísticos, sob a influência de teorias críticas, as quais se refletiram, também, na área da Linguística (SOUSA; PONTE; SOUSA-BERNINI, 2019).

É importante, ainda, ressaltar que as teorias críticas foram fundamentais na área da PPL, posto que trouxeram, como apresentado por Sousa, Ponte e Sousa Bernini (2019), implicações nos estudos desse campo, embora essa influência tenha sido melhor observada apenas na década de 90, quando se materializaram em diferentes construtos teóricos, ressaltando a compreensão da natureza sociopolítica, bem como ideológica do planejamento linguístico. Também, nesse momento, já se visualiza o direcionamento do planejamento linguístico, com Cooper (1989), em 1989, à mudança social, de maneira a compreender o planejamento no campo educacional, a partir da criação da ideia de "planejamento de aquisição".

Fica evidente que, nesta segunda etapa do desenvolvimento da PPL, os estudiosos da língua estavam insatisfeitos com um planejamento linguístico relacionado apenas a um modelo de modernização. Logo, começaram a priorizar, no estudo do comportamento linguístico, o lado social, considerando-se as crenças dos falantes e de suas comunidades, os quais, por consequência, são influenciados pelos fatores políticos, sociais e econômicos.

Esta inquietação configurou o início da terceira etapa, que, originando-se na metade dos anos 1980, conforme mostra Ricento (2000), fez com que os estudiosos recebessem influência das teorias pós-modernas e críticas da área, desencadeando a defesa pelos direitos linguísticos e, inclusive, a elaboração de construtos teóricos-metodológicos para a área da PPL (SOUSA; PONTE; SOUSA-BERNINI, 2019). Nesse pano de fundo, observa-se que, nesta etapa, surgiram diversas perspectivas teóricas, as quais não são todas detalhadas aqui, haja vista o foco desta pesquisa.

\subsection{Política Linguística Disciplinar: rumo a um conceito}

Antes de se pensar na Teoria da Gestão da Língua (TGL), destaca-se a noção de política linguística como um processo teorizado a partir da "metáfora da cebola" cunhada por Ricento e Hornberger (1996). Esta noção defende a política linguística como um processo constituído por diferentes camadas, processos e agentes, oportunizando, dessa maneira, espaço para investigações responsáveis por explorar os processos micro, assim como as relações entre os níveis macro e micro presentes no contexto da política linguística.

Isso é importante porque esses contextos micro e macro permitem reflexões não só no que concerne ao gerenciamento da língua de um ponto de vista top down, mas, também, do ponto de vista das práticas/escolhas e crenças que envolvem o uso da língua em estudo. Nesse percurso se chega, neste estudo, às reflexões de Spolsky (2004; 2009; 2012), estudioso responsável pela TGL, alicerçada em alguns pressupostos, dentre os quais, primeiramente, o de que uma teoria da política 


\section{REVISTA DA ABRALIN}

linguística deve dar conta de escolhas linguísticas. Em outras palavras, para este autor, os usuários da língua realizam escolhas sobre que língua ou variedades linguísticas devem utilizar, em determinados contextos interacionais, considerando-se, por sua vez, os diferentes domínios dos quais eles fazem parte.

Essa noção de domínio utilizada pelo autor, como aponta Sousa e Silva (2020), advinda de Fishman (1972), é considerada o espaço social composto pelos participantes, localização e tópico, sendo os participantes caracterizados pelos papéis sociais que ocupam em relação aos seus interlocutores, como se pode perceber, por exemplo, na universidade, em que o reitor exerce um papel social mais alto na hierarquia acadêmica. A localização, neste caso, conecta a realidade social do participante à realidade física, enquanto que o tópico condiciona os falantes a utilizarem o que pode ser dito de acordo com o domínio no qual se encontram inseridos. Logo, se, no exemplo citado, o reitor está na instituição física universidade, exercendo o seu papel social, deve se portar com um linguajar acadêmico apropriado ao referente meio. Mas, se este mesmo indivíduo estiver em sua casa, junto à sua família, ele se despe do papel social de reitor, apropriando-se do papel social de pai e esposo, utilizando, portanto, um linguajar apropriado ao domínio no qual se circunscreve.

Na continuidade dessas reflexões, com Spolsky (2009), ressalta-se a descrição das políticas linguísticas a partir das dimensões das práticas, crenças e gestão. Tal reflexão nos faz pensar que o processo de publicação em revistas científicas está imbricado a políticas linguísticas situadas, relacionadas a culturas disciplinares das práticas linguísticas, de acordo com o conceito de Política Linguística Disciplinar (PLD).

As Políticas Linguísticas Disciplinares (PLD) devem ser compreendidas no âmbito das comunidades de fala, isto é, dos domínios. Neste trabalho, este conceito é elaborado a partir de análises do domínio acadêmico. Nesse sentido, as PLD se encontram intimamente imbricadas aos subdomínios que, por sua vez, têm conexão com um domínio maior, o acadêmico, conforme ilustrado na Figura 1.

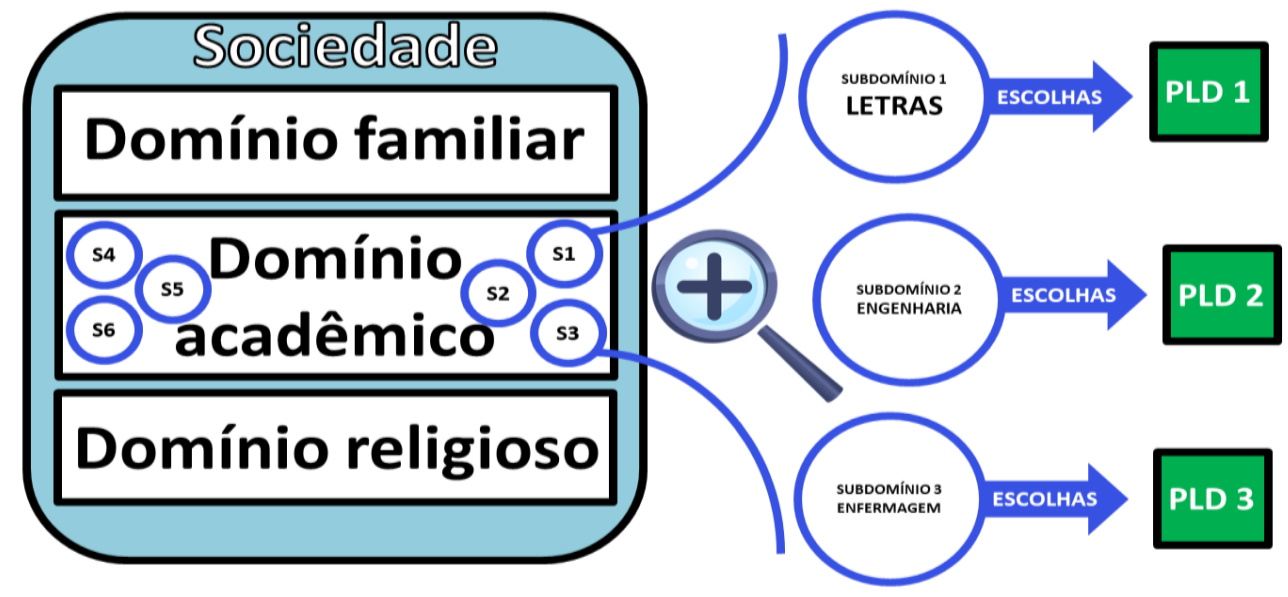




\section{REVISTA DA ABRALIN}

A Figura 1 ilustra como a sociedade comporta diferentes domínios linguísticos, a exemplo do familiar, do acadêmico e do religioso; cada qual com suas especificidades de interação pela linguagem. Assim, entende-se que cada área do conhecimento acadêmico é um subdomínio, com particularidades linguísticas, discursivas, sociais, científicas e políticas e que, por isso, merece ser caracterizada de acordo com suas singularidades.

Nesse percurso, para forjar a ideia de PLD, toma-se como base o que Spolsky (2009, p. 1) apresenta como objetivo da teoria de política linguística: “(...) dar conta das escolhas feitas por falantes individuais com base em padrões regidos por regras que são reconhecidas pela comunidade de fala (ou comunidades) de que fazem parte." ${ }^{8}$. Além disso, parte-se das considerações sobre como as diversas possibilidades de agir pela linguagem guardam semelhanças entre si, como escritores e leitores interagem em práticas acadêmicas, assim como a construção de conhecimento revela especificidades disciplinares (HYLAND, 2014).

Seguindo Hyland (2008), essa interação acontece mediante amplos domínios acadêmicos, em que são desenvolvidas distinções de recursos linguísticos e experiências sociais particulares no interior de disciplinas, as quais oferecem tanto opções retóricas disponíveis aos escritores, bem como padrões de persuasão efetiva empregados por diferentes comunidades. Na investigação dessas distinções, cultura disciplinar é um conceito central em diversos trabalhos de Ken Hyland, no campo da Escrita para Fins Acadêmicos, em Linguística Aplicada. No geral, subjaz ao conceito de cultura disciplinar, pelo que se depreende a partir de Hyland $(2012 ; 2014)$, a observação de que a escrita: 1) é uma atividade central na academia, e esta é vista como um espaço institucional; 2) é uma prática de domínio indispensável para os estudantes experientes desse meio. Em específico, a maneira como os atores de dada instituição escreve, quais gêneros textuais produzem, como constroem estilo em apresentações orais e o modo de marcar posicionamento avaliativo na linguagem revelam diferenças entre disciplinas.

Desse modo, em se tratando do contexto acadêmico-disciplinar, compreende-se que as escolhas, a serem feitas pelos participantes de dada comunidade, apesar de serem individuais, são regidas por normas coletivamente desenhadas por um grupo que as dita e que são específicas, a depender da área disciplinar. Logo, compreender as PLD é vislumbrar, especificamente, a TGL de Spolsky diante das crenças, normas e práticas em cada área do conhecimento.

As PLD, então, partem de duas perspectivas: 1) consideram os aspectos sociais, históricos, discursivos, políticos e linguísticos de dada área disciplinar, de modo a compreendê-la e caracterizá-la em termos de construção, investigação e divulgação do conhecimento científico, a partir de seus participantes, suas localidades e seus tópicos de interesse e de discussão; 2) dispõem, comparativamente, sobre os distanciamentos e as aproximações de campos disciplinares distintos, o que deve contemplar, também, necessariamente, a primeira perspectiva. Assim, neste trabalho, o foco de investigação parte da primeira perspectiva, entendendo que, embora nossa análise compreenda

\footnotetext{
${ }^{8}$ Tradução nossa. Original: “(...) to account for the choices made by individual speakers on the basis of rule-governed patterns recognized by the speech community (or communities) of which they are members." (SPOLSKY, 2009, p. 1).
} 


\section{REVISTA DA ABRALIN}

apenas textos da área da Enfermagem, dentro de uma mesma área disciplinar, podem existir variações quanto aos campos disciplinares de atuação dos pesquisadores.

\section{As práticas de publicação de resumos da Enfermagem: uma análise de Políticas Linguísticas Disciplinares}

Antes de se pensar na Política Linguística Disciplinar presente nas práticas de publicação de resumos da Enfermagem, por meio da análise de textos da revista selecionada para este estudo, vale refletir que atores sociais agem em situações acadêmicas através da produção de diferentes gêneros, quando se encontram em práticas sociais em que precisam entender, produzir e divulgar um conhecimento aceito e validado em seu meio. Produzem esquemas, resumos, resenhas, ensaios, projetos, relatórios, relatos, seminários, debates, exposições orais, monografia, dissertação, tese, artigo científico, dentre outros gêneros textuais com esse poder de potencializar o reconhecimento e/ou a validação de práticas acadêmicas realizadas na construção de conhecimento científico.

Hyland (2014) pensa o conceito de disciplina pelo entendimento de que comunidades fornecem o contexto dentro do qual os alunos aprendem a se comunicar, interpretando os discursos uns dos outros, adquirindo gradualmente as competências linguísticas especializadas para participar como membros de um grupo. A consequência dessa interação é uma variação disciplinar composta por diferentes maneiras de escritores representarem, em campos variados, a eles próprios, seu trabalho e seus leitores. Isso implica o entendimento de que as Ciências Humanas e Sociais assumem posições muito mais envolvidas e pessoais do que aquelas de outros campos da ciência, a exemplo da Enfermagem. Por conseguinte, são impactados os gêneros alvo e as convenções da escrita com os quais os alunos são confrontados em seus estudos.

Diante disso, considerando a importância de se compreender como essa diversidade disciplinar está presente nas práticas linguísticas da área da Enfermagem, reverberando, por consequência, no que se conceituou, neste estudo, como Políticas Linguísticas Disciplinares, são desenvolvidas, a seguir, as categorias de análise desta pesquisa.

\subsection{As normas da Revista Latino Americana de Enfermagem}

É importante lembrar que os periódicos científicos costumam apresentar normas que gerem a elaboração e publicação dos textos submetidos pelos pesquisadores. Essas normas ditam, geralmente, a quantidade de páginas e/ou palavras que devem conter o escrito, assim como as seções que devem compô-lo. Nesse ínterim, é possível observar na citação abaixo as normas apresentadas pela Revista Latino Americana de Enfermagem para composição dos resumos dos artigos científicos. 


\title{
REVISTA DA ABRALIN
}

\begin{abstract}
O resumo deve ser estruturado em: Objetivos, Método, Resultados e Conclusão. Redigido em parágrafo único, em até 200 palavras. O Objetivo deve ser claro, conciso e descrito no tempo verbal infinitivo. O Método deve conter o tipo de estudo, amostra, variável(is), instrumento(s) e o tipo de análise. Os Resultados devem ser concisos, informativos e apresentar principais resultados descritos e quantificados, inclusive as características dos participantes e análise final dos dados. As Conclusões devem responder estritamente aos objetivos, expressar as considerações sobre as implicações teóricas ou práticas dos resultados e conter três elementos: o resultado principal, os resultados adicionais relevantes e a contribuição do estudo para o avanço do conhecimento científico. (RLAE, setembro de 2020).
\end{abstract}

Nota-se, nessas normas, que a revista oferece a possibilidade de o texto possuir, no máximo, 200 palavras, sem estabelecer uma extensão mínima. No entanto, apesar de não oferecer ao pesquisador a possibilidade de extensão mínima, o periódico deixa claro que os textos devem conter objetivos, método, resultados e conclusão. Essa orientação, no que se refere à construção do texto, elucida uma interferência da cultura disciplinar (HYLAND, 2014) da área da Enfermagem, mais especificamente desta revista, na construção do resumo, uma vez que o resumo, a depender da área, pode conter outras seções, tais como contextualização temática ou fundamentação teórica, como é comum em áreas das humanas.

Fica perceptível, também, nessas normas, a necessidade de se especificar os elementos composicionais necessários nos resumos, ao, por exemplo, solicitar que os resultados sejam concisos, informativos e apresentem os principais resultados descritos e quantificados, considerando-se, também, as características dos participantes e a análise final dos dados. Isso vislumbra que os gestores desta revista possuem a crença de que o resumo é um texto semelhante para todos os estudiosos da área, desconsiderando as particularidades das pesquisas, peculiaridades de pesquisas existentes dentro da própria Enfermagem. Essa tentativa parece falha, à proporção que, dada as especificidades diversas das pesquisas, a referida revista, em outubro de 2020, após o número publicado neste mesmo ano, realizou algumas mudanças em sua gestão, como se pode observar nas palavras do próprio periódico abaixo.

O resumo deve ser estruturado em: Objetivo, Método, Resultados e Conclusão. Deverá ser redigido em parágrafo único, com até 200 palavras, no idioma em que o texto for submetido, em espaçamento duplo entre as linhas e com a fonte Times New Roman tamanho 12. Citações de autores, local e ano da coleta de dados e siglas, não devem ser apresentadas. O Objetivo deve ser claro, conciso e descrito no tempo verbal infinitivo. O Método deve conter o tipo de estudo, amostra, variáveis, instrumentos utilizados na pesquisa e o tipo de análise. Os Resultados devem ser concisos, informativos e apresentar os principais resultados descritos e quantificados, inclusive as características dos participantes e análise final dos dados. A Conclusão deve responder estritamente ao objetivo, expressar as considerações sobre as implicações teóricas ou práticas do estudo e as suas principais contribuições para o avanço do conhecimento científico. (RLAE, outubro de 2020).

Nas palavras acima, identifica-se uma mudança no que tange aos elementos solicitados como componentes necessários para conclusão do resumo, o que pode denotar uma mudança na gestão impulsionada pelas práticas dos próprios pesquisadores, os quais, como será visto, nas próximas categorias, não cumpriam com o solicitado pela revista, isto é, apresentação dos principais resultados nas considerações finais do texto. 


\section{REVISTA DA ABRALIN}

Essas reflexões nos fazem pensar nas hipóteses que foram apresentadas nas considerações iniciais deste trabalho, isto é: o fato de as normas apresentadas pela revista científica exercerem o poder de políticas linguísticas top-down sobre os resumos produzidos pelos autores, funcionando como uma força centrípeta, bem como o fato de os resumos publicados nessa revista atenderem às políticas linguísticas por ela normatizada. No entanto, diante das Políticas Linguísticas Disciplinares, o que se percebeu, a partir da mudança das normas da revista em questão, foi uma política linguística bottow-up, uma vez que as especificidades disciplinares (HYLAND, 2014) dos estudos forçaram a revista a considerar as particularidades dentro da própria área da Enfermagem, como será melhor discutido posteriormente.

\subsection{Normativas e práticas da Enfermagem}

Nesta seção, analisa-se como os resumos publicados materializam as normativas da Revista Latino Americana de Enfermagem. Verifica-se se as proposições normativas do periódico são, de fato, atendidas, pensando-se na composição dos textos, diante do limite de palavras, como, também, os elementos solicitados para sua construção. Além disso, um fator observado e característico desse contexto são as práticas dos pesquisadores que, dependendo da área de investigação, apresentam, em seus trabalhos, uma maior quantidade de coautoria, devendo isso a fatores, por exemplo, de trabalhos resultantes de experimentos em laboratório, dentre outros. Isso é bem perceptível na área da saúde, como visto no Quadro 2, apresentado na seção metodológica deste texto.

Considerando as normas da Revista Latino Americana de Enfermagem apresentadas na primeira categoria desta seção, observou-se, ao analisar os 10 resumos de Enfermagem, que não existem resumos que cumprem apenas a norma "de até 200 palavras", mas também textos que estão abaixo deste limite ou acima, sendo 7 resumos com, respectivamente, 163 (E4), 141 (E5), 171 (E6), 163 (E7), 198 (E8), 131 (E9) e 188 (E10) palavras, enquanto 3 dos resumos com, nessa ordem, 207 (E1), 235 (E2) e 229 (E3) palavras. A partir desses dados, retomam-se as indagações colocadas na seção anterior, em torno da quantidade de palavras do texto e sua possível influência no processo de construção desta produção. Faz-se, por isso, interessante observar, a seguir, dois dos resumos ora citados: um com 141 palavras e outro com 235. 


\section{REVISTA DA ABRALIN}

\begin{tabular}{|c|c|}
\hline RESUMO E5 & RESUMO E2 \\
\hline $\begin{array}{l}\text { Objetivo: identificar as associações entre as } \\
\text { variáveis sociodemográficas, laborais, condições } \\
\text { de saúde, hábitos de vida e os riscos de } \\
\text { adoecimento do trabalhador de enfermagem de } \\
\text { um hospital psiquiátrico. Método: estudo } \\
\text { transversal analítico. A amostra de } 74 \\
\text { trabalhadores respondeu a um questionário para } \\
\text { caracterização sociodemográfica, laboral, } \\
\text { levantamento de condições de saúde e hábitos de } \\
\text { vida. Para avaliar a percepção dos riscos de } \\
\text { adoecimento, na opinião do entrevistado, foram } \\
\text { utilizadas a Escala de Avaliação do Contexto de } \\
\text { Trabalho e a Escala de Custo Humano no } \\
\text { Trabalho. Realizou-se análise descritiva e } \\
\text { bivariada, com significância de 5\%. Resultados: os } \\
\text { fatores associados aos riscos de adoecimento } \\
\text { foram: queixas de insônia, trabalho noturno e } \\
\text { jornada de trabalho. Conclusão: há evidências de } \\
\text { que as associações entre as variáveis laborais, } \\
\text { condições de saúde e hábitos de vida podem } \\
\text { prejudicar a saúde da equipe de enfermagem de } \\
\text { um hospital psiquiátrico. }\end{array}$ & $\begin{array}{l}\text { Objetivo: descrever o desenvolvimento de um guia } \\
\text { holístico de debriefing, em inglês e português do } \\
\text { Brasil, focado em enfermeiros educadores para } \\
\text { promover a aprendizagem reflexiva. Método: } \\
\text { estudo metodológico, com três fases: revisão } \\
\text { integrativa de literatura, desenvolvimento do guia } \\
\text { e sua avaliação por um painel de especialistas em } \\
\text { enfermagem. A revisão de literatura seguiu um } \\
\text { processo sistemático. Para o desenvolvimento do } \\
\text { guia, os resultados da revisão de literatura foram } \\
\text { utilizados, juntamente com o processo de } \\
\text { debriefing de Lederman e o referencial de } \\
\text { aprendizagem de Zabala, como base teórica para } \\
\text { promover a aprendizagem reflexiva durante a } \\
\text { Simulação de Alta Fidelidade. O painel de } \\
\text { especialistas em enfermagem analisou a qualidade } \\
\text { do guia. Resultados: a revisão da literatura revelou } \\
\text { lacunas na preparação dos educadores } \\
\text { pedagógicos e a ausência de ferramentas holísticas } \\
\text { de debriefing que incluam os aspectos formativos e } \\
\text { sumativos de orientação em debriefing para } \\
\text { auxiliar os educadores. O guia de debriefing foi } \\
\text { desenvolvido em duas páginas: a primeira página } \\
\text { recomenda como conduzir o debriefing e a } \\
\text { segunda contém perguntas de orientação. O guia } \\
\text { foi avaliado e passou por um total de três } \\
\text { modificações para congruência dos itens avaliados } \\
\text { e adequação dos termos utilizados. Conclusão: foi } \\
\text { proposto um guia holístico de debriefing visando } \\
\text { enfermeiros educadores. Este estudo fornece uma } \\
\text { visão geral do processo para promover a } \\
\text { aprendizagem reflexiva na Simulação de Alta } \\
\text { Fidelidade e contribui para o treinamento formal } \\
\text { de enfermeiros educadores para a aplicação das } \\
\text { melhores práticas pedagógicas. }\end{array}$ \\
\hline
\end{tabular}

\section{QUADRO 3 - Comparação entre os resumos E5 e E2.}

Fonte: Elaboração própria.

Nesse quadro, há dois extremos do corpus da área de Enfermagem selecionado para esta pesquisa, isto é, um dos resumos que apresentam menos e o que apresenta mais palavras. A priori, imagina-se que a extensão do resumo pode gerar a possibilidade de mais ou menos informações e, por conseguinte, um maior ou menor atendimento às normas postas pelo suporte de publicação. No entanto, além disso, é importante, ainda, observar se isso, de fato, é um atenuante ou se, na verdade, o maior atenuante seja a Política Linguística Disciplinar, ou seja, a característica do subdomínio em que se insere a pesquisa como um fator a definir o que se tem ou não no resumo.

Diante dessas considerações, inicialmente, observando o objetivo de ambos os textos, compreende-se que os autores usam os verbos no infinitivo e são concisos, mas, em termos de conteúdo, revelam ser de áreas de pesquisa diferentes, haja vista que o resumo E5 está relacionado a variáveis de segurança do trabalho no ambiente da Enfermagem, enquanto o E2 apresenta uma temática mais direcionada a parte mais humana da Enfermagem, envolvendo a aprendizagem e o seu contexto holístico. Essa primeira percepção traz uma reflexão a respeito do estilo do autor, agente de uma 


\section{REVISTA DA ABRALIN}

prática, que pertence a uma área disciplinar diferente. Supõe-se, ao comparar os resumos apresentados, que, embora estejam publicando em um mesmo suporte, os autores desses trabalhos exemplificados, apesar de pertencentes a uma área disciplinar específica, podem sofrer influência de diferentes ideologias, o que os fazem priorizar uns elementos em detrimento de outros em seus textos. Isso porque, no momento em que submetem o texto para avaliação em um periódico, esses pesquisadores precisam, minimamente, atender às considerações realizadas pelos pareceristas, indivíduos que, apesar de pertencerem, supõe-se, a área da Enfermagem, apresentam suas próprias ideologias, fruto das práticas discursivas nas quais eles se circunscrevem.

Ao observar a apresentação dos métodos em ambos os trabalhos, é perceptível que, embora mais curto, o E5 apresenta uma maior variedade dos elementos solicitados pela norma da revista, uma vez que demonstra tipo da pesquisa, amostragem, instrumento de coleta de dados, bem como procedimento e tipo de análise. Por outro lado, o E2, cuja extensão é maior, parece apresentar mais elementos metodológicos, embora, ao analisar tais elementos em comparação com o solicitado pela revista, identifica-se a presença apenas dos procedimentos realizados no desenvolvimento do estudo, considerando-se o fato de ser um estudo de natureza diferente do outro, o que pode confirmar a influência da área disciplinar nas práticas linguísticas da revista, como já dito.

Essa situação nos faz pensar que, ao solicitar que os autores apresentem a descrição da metodologia a partir de elementos pontuais, a revista situa as pesquisas dentro de um determinado paradigma de pesquisa, eximindo-se da possibilidade de existirem pesquisas que abordem, neste mesmo domínio, outro paradigma. Em outras palavras, as normas apresentadas pelo suporte de publicação parecem transparecer que os pesquisadores da área de Enfermagem devem centrar-se em um paradigma positivista, porém percebe-se que o resumo E2 refuta essa ideia. Pode-se considerar, então, pelas práticas observadas nos textos em questão, que as pesquisas na área da Enfermagem, considerando seu caráter mais empírico e, geralmente, mais experimental, tendem a dar ênfase às informações metodológicas (MELO; PEREIRA, 2020), embora isso não queira dizer, necessariamente, que todas as pesquisas dessa cultura disciplinar (HYLAND, 2014) apresentem uma mesma caracterização metodológica.

Nos resultados apresentados, nota-se a objetividade empregada no resumo E5, atendendo, pois, a uma norma solicitada, mas, em contrapartida, não se tem resultados quantificados. Isso mostra a inconsistência da gestão realizada pela revista, a qual parece compreender que todos os seus pesquisadores possuem as mesmas ideologias, o que os fariam realizar, por sua vez, as mesmas práticas (SPOLSKY, 2004). No entanto, a impossibilidade da semelhança entre essas práticas fica perceptível a partir do momento em que os pesquisadores, apesar de presentes em um mesmo subdomínio, considerando-se o domínio acadêmico como um lugar mais abrangente, apresentam lugares ainda mais específicos, ou subdomínios ainda mais específicos. Esta especificidade é comprovada a partir do momento em que, avaliando o resumo E2, entende-se que, apesar de apresentar mais informações, considerando-se a quantidade de palavras, a seção não atende às normas, uma vez que não é concisa, nem apresenta, como já pontuado, resultados quantificados. Na verdade, apresenta resultados e uma informação metodológica (o procedimento de desenvolvimento do guia do debriefing, como se pode observar no resumo acima). 


\section{REVISTA DA ABRALIN}

Já na conclusão, vê-se que, no resumo E5, diferentemente do que a revista solicita para elaboração desse elemento composicional, ou seja, outros resultados relevantes e a contribuição do estudo para o avanço do conhecimento científico, os autores, no caso deste resumo em análise, apresentam apenas o resultado principal da pesquisa. Neste caso, considerando que o resumo apresenta 141 palavras, haveria ainda 59 palavras para defesa da importância da pesquisa, diante da gestão do limite posta pela revista. Por outro lado, no resumo E2, os autores fazem uma retomada do que foi proposto na pesquisa, apresentando, sumariamente, o que o estudo acomoda, assim como sua contribuição para a área.

Essas considerações reforçam algumas das reflexões realizadas anteriormente, dentre as quais se pensava até que ponto a quantidade de palavras poderia ser um fator atenuante no atendimento das normas da revista. Percebe-se que não se pode considerar este como um fator único, mas que pode, dependendo do estilo do autor e da pesquisa, dificultar o atendimento a essas normas. A quantidade de palavras, nas reflexões aqui realizadas, serve como uma referência para ressaltar que a gestão deve considerar as especificidades de cada tipo de pesquisa, a qual, independentemente do número de palavras a se colocar no texto, nem sempre apresentará todos os elementos postos como necessário na construção, por exemplo, do resumo, como é o caso investigado, neste estudo.

Se por um lado, nos casos analisados, tem-se um texto de caráter mais objetivo, em que, mesmo com a possibilidade de mais informações, os autores optaram por não incluir e, mesmo assim, foram aceitos pela revista; por outro lado, identifica-se um texto com caráter mais robusto, dada a caracterização da pesquisa que apresenta uma revisão da literatura. Essas considerações nos levam a perceber o quanto o tipo de pesquisa influencia, inclusive, na construção da textualização do estudo, reforçando a ideia de uma política linguística disciplinar bottow-up, que, mesmo diante de normas para publicação do periódico, não pode desconsiderar as ideologias presentes em seu subdomínio.

\section{Considerações finais}

Como foi apontado no decorrer das reflexões apresentadas, as PLD se configuram por escolhas deliberadas realizadas pelos sujeitos que compõem culturas disciplinares, de modo que cada área do conhecimento é caracterizada por escolhas singulares, o que implica, consequentemente, em PLD também específicas para cada ramo do saber, disciplinarmente. Na verdade, a compreensão das PLD mostra-se de grande relevância para a compreensão de como se articulam as normatizações e implementações da escrita acadêmica nos diferentes campos do conhecimento.

Ao se saber disso, foi possível verificar que, a partir da análise do periódico analisado, em uma retomada dos objetivos deste artigo: 1) caracterizaram-se as normas da Revista Latino-Americana de Enfermagem como PLD, ao se observar que o periódico deixava claro quais seriam os componentes dos elementos composicionais a serem implementados na construção do resumo acadêmico 2) descreveram-se as práticas de escrita de resumos acadêmicos na revista, como intimamente atreladas às respectivas PLD, embora alguns deles não atendam ipisis litteris às normas das revistas; 3) 


\section{REVISTA DA ABRALIN}

diferenciaram-se as crenças a partir das PLD evidenciadas nas normas e nos resumos da revista, de modo que: a Enfermagem, com suas normas bem detalhadas a respeito da composição das seções que devem compor o resumo, pode dificultar a construção do texto, por não incluir, neste processo de elaboração das normas, a compreensão das especificidades das diferentes variações disciplinares dentro da própria área.

Nesse sentido, tendo em vista a pergunta que norteou a construção deste trabalho: como se caracterizam as políticas linguísticas declaradas e praticadas, em periódico científico da área de Enfermagem?, verificou-se que as políticas linguísticas se fazem específicas para cada periódico, diferenciando-se a depender da área do conhecimento representativa da revista, o que abarca, justamente, uma das noções defendidas no decorrer deste texto: a existência de Políticas Linguísticas Disciplinares (PLD). Destarte, as PLD reverberam na gestão e nas práticas de ambas as revistas, externando crenças em relação ao processo de escrita acadêmica e à própria concepção de ciência para cada área.

Conclui-se que, embora as PLD queiram ser top-down, que almejem poder coercitivo de cima para baixo (conforme supunha a primeira hipótese norteadora deste artigo), elas, na verdade, são articuladas em um continuum ir-e-vir, posto que sofrem influências de baixo para cima. Nesse contínuo, apesar de ser confirmada a segunda hipótese, de que os resumos publicados nas revistas científicas atendem às políticas linguísticas por elas normatizadas, verifica-se que as normas orientam o processo de submissão, sem que todos os seus elementos composicionais precisem, obrigatoriamente, ser mobilizados nas publicações desses periódicos. Logo, esse atendimento acontece porque as normas são orientadoras, não impositivas.

Por conseguinte, as práticas de escrita dos resumos acadêmicos interferem na própria construção das normas de uma revista, o que se pôde perceber a partir da mudança das normas da Revista Latino-Americana de Enfermagem, que, a partir do ano 2020, excluiu do elemento composicional referente às conclusões do resumo acadêmico a presença de aspectos relativos aos resultados da pesquisa. Portanto, as PLD são escolhas disciplinares relativamente fluidas, assim como são as crenças, gestões e práticas da linguagem.

\section{REFERÊNCIAS}

BARATA, R. B. Dez coisas que você deveria saber sobre o Qualis. RBPG, Brasília, v.13, n.1, jan./abr. 2016. Disponível em: http://dx.doi.org/10.21713/2358-2332.2016.v13.1129. Acesso em: outubro 2016.

CAPES - Coordenação de Pessoal de Nível Superior. Relatório da Avaliação Quadrienal 2017: linguística e literatura. 2017. Disponível em:

http://capes.gov.br/images/documentos/Relatorios quadrienal_2017/20122017-

letras_relatoriodeavalia\%C3\%A7\%C3\%A30_quadrienal2017_final.pdf. Acesso em set. 2020.

CAPES - Coordenação de Pessoal de Nível Superior. Qualis Periódicos. 2016. Disponível em:

https://sucupira.capes.gov.br/sucupira/public/consultas/coleta/veiculoPublicacaoQualis/listaConsultaGeral

Periodicos.jsf. Acesso em set. 2020. 


\section{REVISTA DA ABRALIN}

CROKER, R. A. An Introduction to Qualitative Research. In: HEIGHAM, J.; CROKER, R. A. (Edit.) Qualitative research in Applied Linguistics: a practical introduction. Palgrave Macmillan: London, 2009. p. 3-24.

CRESWELL, J. W. Research design: Qualitative, quantitative, and mixed methods approaches. SAGE, 201.3

COOPER, R. Acquisiton planning. In: COOPER, R. Language planning and social change. Cambridge University Press: New York, 1989. p. 157-163.

FISHMAN, J. Domains and the relationship between micro- and macrosociolinguistics. In: GUMPERZ, J. J.; HYMES, D. H. (Orgs.). Directions in Sociolinguistics: the ethonography of communication. New York: Holt Rinehart and Winston, 1972. p. 435-453.

GONZÁLEZ, C.; RIVAS, N. CAPÍTULO 3 - El Artículo de Investigación Científica: regularidades y variación a través de las disciplinas. In: IBÁÑEZ, R.; GONZÁLEZ, C. Alfabetización disciplinar en la formación inicial docente - leer y escribir para aprender. Valparaíso: Ediciones Universitarias de Valparaíso, 2017, p. 65-83.

HYLAND, K. English for Academic Purposes. In: LEUNG, C.; STREET, B. (eds.). The Routledge Companion to English Studies. London: Routledge. 2014

HYLAND, K. ESP and Writing. In: HYLAND, K. The Handbook of English for Specific Purposes (eds B. Paltridge and S. Starfield). 2012.

HYLAND, K. Persuasion, Interaction and the Construction of Knowledge: Representing Self and others in Research Writing. International Journal of English Studies, v. 8, n. 2, Universidad de Murcia. 2008, p. 1-23

JOHNSON, D. C.; RICENTO, T. Conceptual and theoretical perspectives in language planning and policy: situating the ethnography of language policy.m International Journal of the Spciology of Language, n. 219, p. 7-21, 2013.

LIN, A. M. Y. Researcher positionality. In: HULT, F. M.; JOHNSON, D. C. (Orgs.). Research methods in Language Policy and Planning: a pratical guide. UK: Wiley Blackwell, 2015. p. 21-32

MELO, G. N. de. Escrita acadêmica nas áreas da Linguística e Enfermagem: um estudo dos relatórios finais de iniciação científica. Dissertação. 102f. João Pessoa - PB: Universidade Federal da Paraíba, 2019. Disponível em: https://repositorio.ufpb.br/jspui/handle/123456789/18101. Acesso em: nov. 2020.

RICENTO, T. Historical and theoretical perspectives in language policy and planning. Journal of Sociolinguistics, 4,2, 2000, p. 196-213.

RICENTO, T.; HORNBERGER, N. H. Unpeeling the onion: language planning and policy and the ELT professional. Tesol Quartely, v. 30, n. 3, 1996, p. 401-427.

RODACKI, A. L. F. Qualis: implicações para a avaliação de programas de pós-graduação das diferentes áreas do conhecimento - uma análise preliminar. RBPG, Brasília, v.13, n.1, jan./abr. 2016. Disponível em: http://dx.doi.org/10.21713/2358-2332.2016.v13.947. Acesso em: outubro 2016.

SILVEIRA, D. T.; CÓRDOVA, F. A pesquisa científica. In: GERHARDT, T. E.; SILVEIRA, D. T. (orgs.). Métodos de pesquisa. Coordenado pela Universidade Aberta do Brasil - UAB/UFRGS e pelo Curso de Graduação Tecnológica - Planejamento e Gestão para o Desenvolvimento Rural da SEAD/UFRGS. - Porto Alegre: Editora da UFRGS, 2009, p. 31-42. Unidade 2 Disponível em: http://www.ufrgs.br/cursopgdr/downloadsSerie/derad005.pdf. Acesso em: 12 de mar. 2020. 


\section{REVISTA DA ABRALIN}

SOMA, N. Y.; ALVES, A. D.; YANASSE, H. H. O Qualis Periódicos e sua utilização nas avaliações. RBPG, Brasília, v.13, n.1, jan./abr. 2016. Disponível em: http://dx.doi.org/10.21713/2358-2332.2016.v13.1128. Acesso em: outubro 2016.

SOUSA, S. C. T.; PONTE, A.; SOUSA-BERNINI, E. N. B. A área de Política e Planejamento Linguístico no cenário internacional e nacional. In: SOUSA, S. C. T.; PONTE, A.; SOUSA-BERNINI, E. N. B. (Orgs.). Fotografias da Política Linguística na pós-graduação no Brasil. João Pessoa: UFPB, 2019. p.5-50.

SOUSA, S. C. T.; SILVA, M. E. M. O estatuto e as crenças de estudantes do PEC-G em relação à língua portuguesa: "o português é muito importante.". Prolíngua, v. 15, n. 1, 2020.

SOUSA, S. C. T.; SOARES, M. E.; DIONÍSIO, C. I. B. Introdução ao estudo da Política e Planejamento Linguístico. (no prelo).

SPOLSKY, B. Language policy: key topics in Sociolinguistics. Cambridge: Cambridge, 2004.

SPOLSKY, B. Towards a theory of language policy. In: SPOLSKY, B. Language Management. Cambridge: Cambridge University Press, 2009. Cap. 1, p. 01 -09.

SPOLSKY, B. The Cambridge Handbook of Language Policy. Cambridge: Cambridge University Press, 2012.

STREET, B. Academic Literacies approaches to Genre?. Revista Brasileira de Linguística Aplicada, Belo Horizonte, v. 10, n. 2, p. 347-361, 2010. Acesso em: 8 abr. 2021.

SWALES, J. M. Genre analysis: English in academic and researching settings. Cambridge: Cambridge University Press, 1990. 